\title{
LA ANDANTE ESCUDERÍA DE DON PEDRO CALDERÓN DE LA BARCA*
}

\author{
José Montero Reguera \\ Universidade de Vigo \\ jmontero@uvigo.es
}

\begin{abstract}
"Caballero andante»: "el héroe fingido o fabuloso de cuya historia se componen los libros de caballerías' (Diccionario de autoridades).

«Caballero andante»: 'Por translación se llama también al hombre de buen nacimiento que no tiene ocupación alguna y anda todo el día de una parte a otra gastando el tiempo inútilmente; y así se dice Fulano es un caballero andante, está hecho un caballero andante' (Diccionario de autoridades).
\end{abstract}

\section{Cervantes y Calderón una vez más}

L as huellas más claras que Cervantes deja en Calderón pueden reconstruirse a partir de la existencia de una comedia, hoy perdida, posiblemente burlesca, con el título Don Quijote (o Los disparates de don Quijote) (Cruickshank, 2011: 501 y 508; Madroñal Durán, 2012), así como alusiones explícitas al escritor y su obra en distintas piezas (empezando por El alcalde de Zalamea), que han sido registradas y analizadas por investigadores muy diversos, a partir de Sánchez (1957), Wilson (1982), Meregalli (1995), Arellano (1999) y Cruickshank (2011), en una lista de referencias bibliográficas que va siendo cada vez más extensa ${ }^{1}$.

* Este trabajo se inserta dentro de los trabajos desarrollados por el grupo de investigación «Ediciones y estudios de literatura española» de la Universidad de Vigo y del proyecto de investigación «El Quijote transnacional», bajo la dirección de Javier Pardo (Universidad de Salamanca), con referencia PGC2018-093792-B-C21. Agradezco a mis colegas Zaida Vila Carneiro, Abraham Madroñal Durán, Santiago Fernández Mosquera y Germán Vega García-Luengos los materiales proporcionados y sus comentarios a versiones previas de este trabajo.

1 En orden alfabético: Abrams (1966), Arellano (1999), Canavaggio (1988), Close (2011), Cruickshank (2011), Escalonilla López (2002), Meregalli (1995), Regalado (1999), Sáez (2013), Sánchez (1957), Suárez Miramón (1999), Torres (1998a: 1998b), Valbuena Briones (1965; 1977) y Wilson (1982). Esta influencia podría complementarse con la de los libros de caballerías, que abre

Edad de Oro, XL (2021), pp. 555-579, ISSN: 0212-0429 - ISSNe: 2605-3314

DOI: https://doi.org/10.15366/edadoro2021.40.025 


\section{UN PEQUEÑO MARCO TEÓRICO Y DE INVESTIGACIÓN}

Quiero situarme en este camino para estudiar un detalle mínimo, una expresión y algunos de sus derivados, que ofrecen un aspecto más del intenso eco que Cervantes, sobre todo el Quijote, tiene en el teatro de Calderón; ayuda, por una parte, a refrendar y comprender el modo con el que se recibió el libro del alcalaíno: para hacer reír, con sentido cómico ${ }^{2}$. De otra parte, ofrece un pequeño corpus de cómo Calderón encuentra en la literatura cervantina elementos diversos que contribuyen a enriquecer la parte cómica de sus comedias, a potenciarla, en todo caso. En otras palabras, lo que Calderón usa en su teatro procedente de Cervantes va generalmente unido a lo cómico.

Desde esta perspectiva, mi propuesta de hoy se inserta en el camino del replanteamiento que se viene ofreciendo desde hace tiempo, con Luis Iglesias Feijoo a la cabeza de sus mejores exponentes, de la figura de Pedro Calderón de la Barca, no tanto como representante de la intolerancia, de la religión ultramontana, serio, adusto, imagen esta que crearon algunos pensadores alemanes a comienzos del siglo XIX; cuanto de ese otro Calderón que poseía un «agudo y despierto sentido del humor», autor de muchas obras «llenas de gracia y situaciones cómicas, en las que domina un vivo sentido del humor, tanto en la vertiente lingüística como en la ironía metaliteraria y metateatral» (Iglesias Feijoo, 2016: 330). Un escritor, en definitiva, mucho más complejo y lleno de matices que desborda una imagen que no le hace justicia, por errónea y empequeñecedora; porque conviene no olvidar nunca que

Calderón es tanto el autor de los autos sacramentales como de La dama duende, de El príncipe constante lo mismo que Casa con dos puertas. Solo cuando logremos entender dialécticamente ambas facetas y otras complementarias, estaremos en disposición de comprender de verdad a un autor mucho más rico de lo que entendieron no pocos de sus exégetas (Iglesias Feijoo, 2004: 159).

Para el desarrollo de esta propuesta me moveré en el pequeño mundo de la referencia microtextual, tal como la define Ignacio Arellano³.

otro camino interesante que se puede rastrear a través de diversas obras como La puente de Mantible, hasta la última que escribió, Hado y divisa de Leonido y Marfisa, pasando por El jardín de Falerina, El conde Lucanor o El castillo de Lindabridis. A ellas se han referido, con distinto alcance, Díez Borque (2000) y Rodríguez Gallego y Sáez (2016: 45-51).

2 Véase las síntesis que ofrezco en Montero Reguera (1997: 104-115; 2005a: 15-26; 2011, passim).

3 «Denominaré referencias microtextuales a las menciones ocasionales que se expresan en muy pocos versos (entre dos y doce), sin que articulen ningún esquema argumental ni la definición de los personajes, a los que solo confieren pequeños rasgos no esenciales. Generalmente suponen una asociación jocosa, o dan pie a un juego de ingenio a partir de la evocación intertextual, constituyendo una agudeza por alusión a textos conocidos por el público, que se complace en reconocer la broma» (Arellano, 1999: 13). 


\section{Escuderos ANDANTES: Avellaneda y CERVANTES}

He aquí el punto de partida: del mismo modo que hay un caballero andante en el libro de Cervantes, también se halla un escudero andante; en realidad hay un «malandante escudero», como así se describe a Sancho en el capítulo 49 de la primera parte: «En estas pláticas se entretuvieron el caballero andante y el malandante escudero, hasta que llegaron donde ya apeados los aguardaban el cura, el canónigo y el barbero» (Cervantes, 2015: 613). A la tradición que une «malandanza» con mala fortuna, «escudero sin fortuna» en este caso (Rico, 1990: 147-147), se une una construcción peregrina por extensión, es decir, de creación de «voces por adición de sílabas o formación de compuestos», procedimiento al que nuestro novelista era bien aficionado (Montero Reguera, 2005b: 13). Cervantes, sin embargo, no era original en el uso de este adjetivo, pues algunos libros de caballerías lo usan con profusión: Tristán de Leonís, Palmerín de Olivia, Primaleón, etc. Su originalidad reside en aplicárselo al escudero, cosa inédita hasta la fecha (véase CORDE). Aún aplicará Cervantes el adjetivo en varias ocasiones (dos más en la primera parte, cuatro en la segunda), pero en ningún caso a Sancho. Nunca, en la primera parte, se asociarán «andante» y «escudero». La unión de estas palabras se debe a Alonso Fernández de Avellaneda en cuyo libro, como anota Gómez Canseco, «Sancho se transforma en escudero andante para asimilarse cómicamente a su amo» (Fernández de Avellaneda, 2014: 149). Y al menos en tres ocasiones lo hace así (2014: 149; 243, con el complemento del neologismo «andantesca escudería»; 335). El propio Cervantes sí lo utilizará ya en la segunda parte de 1615, en boca de Teresa Panza: «—¡Ay, señor mío, quítese de ahí, no haga eso — respondió Teresa-, que yo no soy nada palaciega, sino una pobre labradora, hija de un estripaterrones y mujer de un escudero andante, y no de gobernador alguno!» (2015: 1.132). No hay —al menos no se recoge en CORDE - ninguna referencia previa a Avellaneda.

Con una singular salvedad, esta expresión no tendrá mucho recorrido más allá de Cervantes: el CORDE solo registra dos casos aislados. Uno relativamente temprano pues remite a 1622, del conde de Villamediana: «Siguió sus pasos Darinel, escudero andante» (La gloria de Niquea); y otro bastante posterior procedente de la Olla podrida a la española de Marcos Fernández (1655): «[...] mi amo aguardad a vuestro embaxador y escudero, que el rucio no está enseñado a correr ni jamás rucio de escudero andante corría ni tal se allara, aunque sea en el brebario del cura de mi lugar». 


\section{LA ANDANTE ESCUDERÍA DE CALDERÓN: APROXIMACIÓN AL CORPUS}

La salvedad es Pedro Calderón de la Barca, que emplea la expresión en no menos de ocho ocasiones; y todas en la persecución de momentos graciosos, divertidos, lúdicos, de inequívoca comicidad. En orden cronológico son las siguientes (Cruickshank, 2011: 500-506):

- Peor está que estaba (¿1630?), incluida en la Primera parte de comedias (1636).

- La puente de Mantible (¿1630?), incluida en la Primera parte de comedias (1636).

- Basta callar (1638-1639), incluida en la Quinta parte de comedias (1682).

- La fiera, el rayo y la piedra (1652), incluida en la Tercera parte de comedias (1664).

- Cada uno para sí (¿1653?), incluida en la Parte quince, comedias nuevas escogidas (1661).

- Fortunas de Andromeda y Perseo (1653), incluida en la Parte veintiuna de comedias nuevas escogidas (1663).

- El castillo de Lindabridis (¿1661-1663?) (Leija, 2009), incluida en la Novena parte de comedias (1691).

- Fieras afemina amor (1671), incluida en la Quinta parte de comedias (1677).

Si la presencia de caballeros andantes en el teatro de Calderón ha sido destacada y estudiada con relativo pormenor ${ }^{4}$, en cambio, no lo ha sido el de la singular presencia de escuderos andantes en el mismo corpus. A tal propósito se conduce el siguiente repaso de textos y del contexto en que se insertan.

\section{TEXTOS Y CONTEXTO DE LAS MENCIONES CALDERONIANAS}

\subsection{Peor ESTÁ QUe estaba}

De esta comedia se ha destacado su ambiente aristocrático y su intriga novelesca llena de amores cruzados, nombres fingidos, equívocos, juegos en torno a los mantos de las damas, tramoyas, trazas (el propio texto insiste en esto reiteradamente), palabras que se malinterpretan y, en especial, «notables guiños metateatrales del gracioso» (Iglesias Feijoo, 2006: XLI). Es dentro de este aspecto donde

$4 \quad$ Véase Cruickshank (2011: 501 y 508) y Madroñal Durán (2012), donde se encontrarán materiales abundantes a este respecto. 
cabe incluirse, entre otros muchos, la expresión que me ocupa. En este caso es Camacho, el criado de don César de Urbino, quien la pronuncia ya avanzada la tercera jornada:

$\begin{array}{ll}\text { CAmacho } & \text { A saberlo yo, os hiciera } \\ \text { en eso poco favor, } & \text { pero no puedo decirlo, } \\ \text { porque yo no sé quién soy. } & \text { Tan encantado me tiene } \\ \text { un amo que Dios me dio, } & \text { que ya no sabré de mí } \\ \text { que ando en las selvas de amor } \\ \text { a lo de escudero andante, } \\ \text { siguiendo embozado un sol. } \\ \text { Y, hablando en capa y espada, } \\ \text { aquí busco a la mayor } \\ \text { invencionera de Europa; } \\ \text { si es alguna de las dos } \\ \text { una dama que está aquí } \\ \text { presa, por un solo Dios } \\ \text { me lo diga, porque vengo } \\ \text { peregrino en estación } \\ \text { solo a verla; que mi amo } \\ \text { la cabeza me quebró } \\ \text { su belleza encareciendo, } \\ \text { y quisiera verla yo } \\ \text { a trueco de que me deje } \\ \text { (Calderón, 2006: 929-930). }\end{array}$

Como se puede observar, es una intervención trufada de guiños metaliterarios: comienza con la expresión «yo no sé quién soy», de posible ascendencia quijotesca (Cervantes, 2015: 79), a la que sigue otra («encantado»), que une la novela cervantina con la de caballerías, para engarzarla con «escudero andante», con un conector aliterativo de por medio: «encantado» / «ando» / «andante», que no deja de ser asimismo una derivación léxica. Continúan las referencias, pues el verso siguiente conduce directamente a una expresión metateatral: «Y, hablando en capa y espada». Por otra parte, algo parecido sucede en el que dice «que ando en las selvas de amor», acaso de resonancia lopesca: La selva sin amor fue la primera ópera estrenada en España (Alcázar de Madrid, 18 de diciembre de 1627) sobre un texto de Lope de Vega y música de Bernardo Monanni en colaboración con Filippo Piccini. La fecha de estreno de la ópera y de la posible redacción de la comedia calderoniana no están muy alejadas. 
La expresión del criado se incorpora además en el seno de una conversación de aquel con Lisarda y Celia, dama y criada, que remata con un juego de palabras —léxico y eufónico — en torno al verbo andar, al que siguen otros:

$\begin{array}{ll}\text { Celia } & \text { ¿Cómo sin más atención } \\ \text { OA entráis aquí? } & \\ & \text { Entré andando; } \\ & \text { si os he ofendido a las dos, } \\ & \text { andando me volveré } \\ & \text { al mismo compás y son. } \\ & \text { De lo cierto y lo galano } \\ \text { del danzar se me pegó } & \text { que pie derecho deshaga } \\ & \text { lo que pie izquierdo empezó; } \\ & \text { y así me iré donde vine. } \\ & \text { Decid, soldado, ¿quién sois? }\end{array}$

(Calderón, 2006: 930).

Conviene recordar, por otra parte, que es texto en el que es posible encontrar no solo un escudero andante, sino también una «dama andante», en el seno de otra intervención de Camacho con notable metaliteratura de por medio ${ }^{6}$, y que el mismo criado se autodefine como «[...] Soy un escudero / deste caballero andante» (Calderón, 2006: 887).

\subsection{LA PUENTE DE MANTIBLE}

El motivo caballeresco que origina La puente de Mantible (Calderón, 2006; Rodríguez Gallego y Sáez, 2016) ayuda a entender (y preparar) la incorporación del sintagma que estoy estudiando; como se ha destacado, la comedia está inspirada en la Historia del emperador Carlo Magno y de los doce pares de Francia que Nicolás de Piamonte publicó en Sevilla, en 1525, traducción a su vez de una auténtica «enciclopedia de fábulas carolingias» — en expresión de Francisco Márquez Villanueva-, el Fier a Bras aparecido en Ginebra en 1478. Calderón, como afirma Renata Londero, se

\footnotetext{
Los énfasis en todas las citas son míos.

6 «САMACHO ¿No oíste / a un pasajero, cuando aquí veniste, / que en Nápoles por cierto se decía / que en un convento Flérida vivía? / Mas por lo que hemos dicho / de aquella dama andante del capricho/ singular, ella viene; / y aquí lugar acomodado tiene / lo de lupus in fabula, que quiere / decir, según colijo, / que así Lope a sus fámulos lo dijo» (Calderón, 2006: 881). Véase el comentario y aclaración de este pasaje en Torres (1998b: 580-583).
} 
apodera de una historia sobre la guerra entre Carlo Magno y los sarracenos capitaneados por el emir de España Balán y su hijo Fierabrás, y el par de Francia Guy de Borgoña, que de tanto éxito seguía gozando en España, si Cervantes irónicamente la citaba en los caps. X, XI y XLIX de la primera parte del Quijote (1998: 901).

En esta historia, que se remonta a un lejano cantar de gesta francés del siglo XII, el relato se construye a partir de la lucha entre francos y sarracenos y la ayuda que ofrece la guerrera árabe Floripes, por amor a uno de ellos, Guy de Borgoña, a los pares de Francia, quienes se hallan prisioneros en una torre encantada. Y en su desarrollo tiene especial importancia la llegada de Carlo Magno al puente que separa los dos ejércitos enemigos, custodiado por el gigante Galafre; especial importancia que se resalta por hallarse esta escena justo en el centro de la segunda jornada y porque incorpora a la comedia la parte fundamental de su comicidad, como contrapunto lúdico y divertido de una historia de tenor completamente distinto al que se había venido desarrollando hasta entonces. En este momento es cuando alcanza singular papel el gracioso de la pieza teatral, Guarín, quien, acompañando a Roldán, comienza su intervención con un cómico juego de palabras:

Gúrín que esa palabra das,
con la tal palabra dada
dijiste gran palabrada;
yo, que palabra no di,
no palabré y desde aquí
puedo volverme, que no
me entiendo con agua yo
verde sin lipis
(Calderón, 2006: 524).

Al encomendársele que se dirija hacia el gigante junto con Roldán, la respuesta permite plantear una posible ascendencia quijotesca y prepara la autodefinición de después:

$\begin{array}{ll}\text { ROLDÁN } & \text { Pues ¿qué te acobarda? } \\ \text { GuARÍN } & \text { ¿Giganticos hay también, } \\ & \text { sin ser día del Señor? } \\ & \text { Pues óyeme: plegue al cielo } \\ & \text { que mil demonios de un vuelo } \\ & \text { me arrebaten con rigor } \\ & \text { deste brazo y desta pierna } \\ & \text { y que me arrastren inquietos }\end{array}$

$7 \quad$ Aquí la cita de Márquez Villanueva arriba recogida. 


\section{por montes y vericuetos \\ de la Majestad eterna, si ánimo para que aguarde \\ a ver el gigante tengo \\ (Calderón, 2006: 525).}

No tengo duda que esta inicial respuesta («Gigantitos hay también») combina una alusión doméstica en referencia a los gigantes que acompañaban las fiestas del Corpus en diversas localidades del centro peninsular (Rodríguez Gallego y Sáez, 2016: 120) con una expresión similar de don Quijote que acabó haciéndose proverbial: «—¿Leoncitos a mí? ¿A mí leoncitos, y a tales horas?» (Cervantes, 2015: 831); y se encadena con un desiderátum que le exima de ir y venir («andar») por lugares dificultosos («plegue al cielo / que mil demonios de un vuelo / me arrebaten con rigor / deste brazo y desta pierna / y que me arrastren inquietos / por montes y vericuetos» [Calderón, 2006: 525]). La suma de ambos recursos prepara la afirmación posterior, no sin llamativo juego aliterativo habitual en este tipo de pasajes:

GuARÍN (Él es con buen modo
gigante sanalotodo.
Hoy su manjar he de ser,
ya que mi suerte cruel
me trae de escudero andante
a ganapán de gigante
y he de caber dentro de él)
(Calderón, 2006: 529).

\subsection{BASTA CALLAR}

En esta comedia (Calderón, 2000), Margarita, dama noble de alta alcurnia, hija del duque de Fox, le cuenta a su criada (Flora) cómo en una jornada de caza encuentra tendido y herido a un caballero, a quien rescata; este rescate conduce a que la dama se enamore de aquel: «[...] y más si pasas / a considerar, ¡ay Flora! / que sobre finezas tantas, / siendo él favorecido / es ella la enamorada» (Calderón, 2000: 101, vv. 254-258). Viene en busca de este caballero su criado, Capricho, que llega directamente al jardín donde dama y servidora están conversando. La aparición del criado da un cambio en el tono de la conversación sostenida por aquellas, pues introduce de seguido dos chistes para expresar cómo se ha quedado quieto ante la presencia de ambas: «[...] me ha dejado hecho una estatua» (I, v. 306); y «[...] ¿Quién eres? / Un escudero / andante, antes que llegara / aquí, pero ya parante / lo soy» (Calderón, 2000: 103, vv. 314-316). Si en 
el primero el gracioso acude a una frase hecha que además incluye un posible juego metaliterario con una obra del propio dramaturgo, Amor, honor y poder ${ }^{8}$, la segunda incluye un juego de palabras muy exclusivo del escritor madrileño («andante» / «parante»; fuera de este escritor, el CORDE no registra sino un par de entradas procedentes del Libro de las batallas, relato breve tradicional de en torno a 1600). Calderón lo usará al menos en El escondido y la tapada (h. 1636) y Céfalo y Pocris (1651).

La referencia a su condición de escudero andante («sin fortuna», pero también, que «anda», que «se mueve») se ha preparado e insinuado desde unos versos antes, pues la entrada en escena de Capricho viene dada por una llamativa frase exclamativa puesta en su boca que alude a ese movimiento incesante: « ¿Que en todo hoy no haya / dado con él!» (Calderón, 2000: 102, vv. 294-295). Abierto este camino, el gracioso lo recorrerá en sus respuestas a Flora, quien también entra en él, por medio de la sucesión de dilogías («plantas», v. 296), un políptoton («movéis», «moverlas», «mueve») que forma parte de un campo semántico en torno a la idea de movimiento («volvéos») en el que no falta el juego de contrarios anticipador («quedarme», «irme»), rematado con otra derivación («estuviera», «estando»):

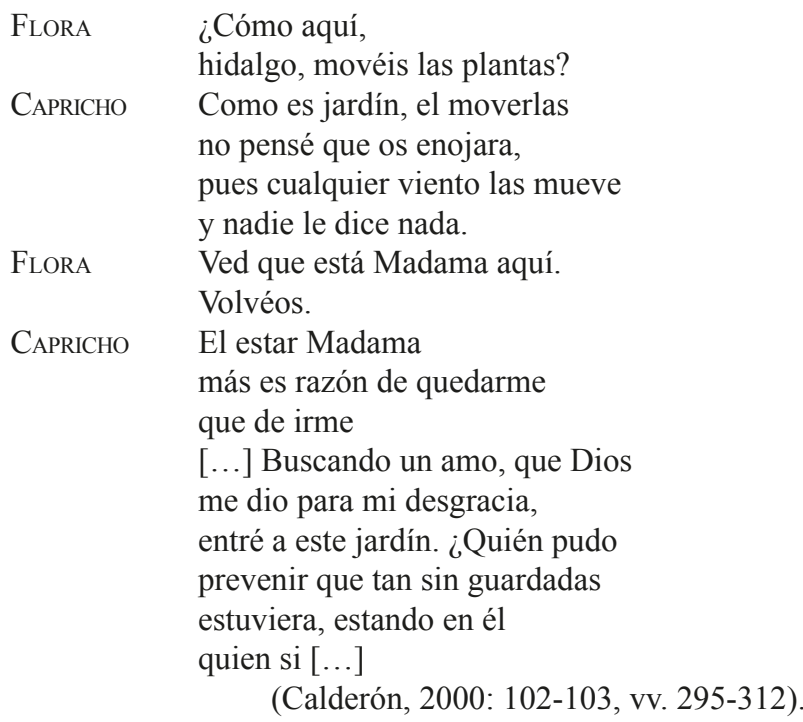

\footnotetext{
$8 \quad$ Así lo propone Rich Greer en su edición de la comedia, Calderón (2000: 278). No obstante, más allá de la referencia a la estatua y de que suceda en un jardín la dependencia con respecto de Amor, honor y poder no parece tan convincente. Véase Calderón (2017: 222).
} 
Todo ello conduce naturalmente a la expresión y juegos de contrarios supradicha.

\subsection{LA FIERA, EL RAYO Y LA PIEDRA}

La parte cómica de esta espectacular comedia (Calderón, 1989c), concebida para el cumpleaños de la reina Mariana de Austria y escrita probablemente en 1652, reside en la participación de tres graciosos, Lebrón, Pasquín y Brunel (en consonancia con los tres asuntos o argumentos de aquella); y desde esta perspectiva es como pueden entenderse las dos menciones andantescas; la primera en boca de Lebrón, con juegos aliterativos y derivativos evidentes:

LEBRón Que haya andantes que anden por selvas encantadas, malo es, vaya, pero peor por selvas es encantadas y cantadas

(Calderón, 1989c: I, 220, vv. 1.127-1.131)9.

La segunda en boca de otro criado, Brunel, a modo de desiderátum (algo parecido a lo acontecido en La puente de Mantible) y contrapunto jocoso a la materia caballeresca, pues no ha de olvidarse que el nombre remite al del escudero de Orlando en el poema épico de Ariosto:

Brunel ¡Plegue al cielo que él por su piedad me saque de escudero andante

(Calderón, 1989c: III, 345, vv. 3.250-3.252).

Una vez más, la mención, aunque lejana, a andantes en el primer acto prepara el camino para la exclamación de Brunel, que también se explica como contribución a la parte cómica de esta obra.

9 Estos versos no quedan lejos de estos otros, muy anteriores, correspondientes a Amor, honor $y$ poder (1623) en boca del gracioso Tosco: «(¡Por san Pito que parecen / aventuras que en los montes / a los andantes suceden! / Mas no va hasta aquí muy malo, / pues no hay quien de mí se acuerde)» (Calderón, 2017: 232, vv. 2.204-2.208). Agradezco a Zaida Vila Carneiro el haberme llamado la atención sobre este pasaje. 


\subsection{CADA UNO PARA SÍ}

En esta comedia de capa y espada la referencia a «escudero andante» se produce muy al comienzo, cuando un galán (D. Félix) y su criado (Hernando) llegan de noche a Toledo y este muestra su enfado sin aclarar las razones que lo originan por medio de una serie de recursos cómicos que actúan de contrapunto a las intervenciones del noble. Se encadena así una serie de juegos de palabras, de contrarios y derivativos (Calderón, 1982: 146, vv. 32-35), refranes («las palabras y plumas / todas se las lleva el viento» [Calderón, 1982: 146, vv. 49-50] y un chiste sobre médicos (Calderón, 1982: 148, vv. 82-84). La conversación entre ambos se interrumpe por el ruido de unas espadas; una dama ( $\mathrm{D}$. ${ }^{\mathrm{a}}$ Violante) le pide ayuda porque la contienda es desigual: un caballero lucha contra tres. El galán acude de inmediato a socorrer al que está en desventaja, cosa que el criado no hace. La dama se lo recrimina y Hernando contesta con una intervención en la que combina un juego de contrarios en torno a la idea de movimiento reforzado por una fórmula proverbial (Vitse, 1984: 117), otro de palabras por disemia para no quedar mal ante su amo («lado» / «ladear») y una afirmación de cómo han de ser y comportarse los criados:

\begin{tabular}{|c|c|}
\hline VIOLANTE & ¿Por qué vos también no vais? \\
\hline HERNANDO & Porque yo ni voy ni vengo. \\
\hline INÉS & $\begin{array}{l}\text { ¿Al lado de vuestro amo } \\
\text { no os ponéis? }\end{array}$ \\
\hline HERNANDO & $\begin{array}{l}\text { Fuera mal hecho } \\
\text { tomar yo el lado a mi amo, } \\
\text { que en todo acontecimiento } \\
\text { parecen bien los criados } \\
\text { encogidos y modestos } \\
\text { sin ladearse con sus amos } \\
\text { (Calderón, } 1982: 148, \text { vv. } 83-91)\end{array}$ \\
\hline
\end{tabular}

Esta conversación previa sirve para crear el contexto adecuado en el que integrar la expresión «escudero andante», que se rodea de recursos y procedimientos comunes en el quehacer de Calderón:

HERNANDO ¿Cuándo, señor, será, el día
que me saquéis de escudero
andante y me hagáis por arte
lacayo de un cura viejo,
que no sepa que en el mundo
hay más duelo que los duelos
de su pecho, su estangurria
y su tos

(Calderón, 1982: 152, vv. 185-192). 
Se unen el desiderátum («¿Cuándo será el día?...»), la autorreferencia a la condición de escudero («lacayo de cura viejo»), el juego de palabras por dilogía y derivación («duelo»: 'aflicción', 'sentimiento'; «duelos»: ‘dolores') y la trimembración léxica, que permite desarrollar un campo semántico sobre los achaques de un hombre anciano: dolores de pecho, incontinencia urinaria y tos. Todo ello constituye además un juego de contrarios entre el punto de partida («andante») y el deseo al que se quiere llegar, implícitamente un escudero sedente o, como en algunas ocasiones, «parante».

\subsection{FoRTUNAS DE ANDROMEDA Y PERSEO}

En este drama mitológico, concebido para ser representado en el Coliseo del Buen Retiro de Madrid el 18 de mayo de 1653 con acompañamiento de música y compleja escenografía, la mención a escudero andante se incluye casi al final del segundo acto donde se da el contexto espacial («selvas») y de acción (un mar adverso que ha dispersado las naves de Perseo) que así lo permite:

Sale Perseo vestido de galán y Bato, de soldado ridículo.

$\begin{array}{ll}\text { PeRSEO } & \text { ¿Qué intrincada selva es esta } \\ & \text { donde las iras crueles } \\ \text { del mar nos han derrotado? } & \text { ¿Muy lindo descuido es ese! } \\ \text { BATO } & \text { ¿Pues a quién se lo preguntas? } \\ & \text { ¿Sé yo más de que, imprudente, } \\ & \text { después que de aquel infierno } \\ & \text { que te he contado otras veces } \\ & \text { salí, te hallé de una armada } \\ & \text { general, y por hacerte } \\ & \text { lisonja quise seguirte, } \\ & \text { pasándome neciamente } \\ & \text { a ser escudero andante? } \\ & \text { ¿Sé más de que tus bajeles, } \\ & \text { embestidos de las Furias } \\ & \text { que desatadas te ofenden, } \\ & \text { apartados unos de otros, } \\ & \text { todos de vista se pierden? } \\ & \text { ¿Sé más que por tomar tierra } \\ \text { en un esquife te metes } & \text { conmigo? Pues ¿qué me haces } \\ \text { preguntas impertinentes? } & \text { Mira si acaso descubres }\end{array}$


población, cabaña o gente por aqueste despoblado. Sígueme por esta parte; allí las ramas se mueven

(Calderón, 2010: 64).

Un contexto y personaje similares (gracioso) permiten que se repita la mención, esta vez para amo y criado:

Salieron Bato y Perseo con el escudo y caduceo.

Perseo Si no me mienten las señas, allí del caduco Atlante, allí de noble alquería, allí de intrincado parque, éste es el sitio que vengo buscando.

Bato Así Dios te guarde, que si no es contra etiqueta de caballeros andantes decir a sus escuderos algunos de los dislates que se les ponen en testa, que me digas qué te trae a estos africanos montes, con tanta prisa

(Calderón, 2010: 73)

\subsection{EL CASTILLO DE LINDABRIDIS}

Esta espectacular comedia caballeresca inspirada en El caballero del Febo, el libro de caballerías de Diego Ortúñez de Calahorra, incorpora la referencia al comienzo de la segunda jornada, en el seno de una intervención del gracioso Malandrín con claro propósito de atraer de nuevo la atención del espectador, acaso todavía un tanto frío tras el espacio transcurrido desde el final de la primera jornada, más aún en una comedia desprovista de entremés (Torres, 1987: 34-35). El gracioso encadena una serie de referencias metateatrales («comedia», «música», «entremés») ${ }^{10}$, que sirve además de afirmación de la autoría del texto:

\footnotetext{
10 «Después de la salpicada, / mil instrumentos oí: si fuera comedia, aquí / acabara mi jornada: / mas puesto que no lo es, / y que prosiguiendo va, / la música suplirá / ausencias del entremés» (Calderón, 1691: s.p., 131, vv. 1.039-1.046).
} 
Por lo menos extrañeza

será de ingenio saber

que hoy todo cuanto hay que ver

es cortado de una pieza

(Calderón, 1691: s.p., vv. 1.047-1.050, p. 131;

Granja, 2000).

Una vez que se ha hecho entrar al espectador de nuevo en la comedia conviene recordarle el tema esencial de la misma (caballerías) y a ello dedica los versos siguientes, que rematan con el sintagma de ascendencia cervantina:

Y esto aparte, ¡vive Dios

que él se ha puesto en el caballo!

Ya nunca podrá parallo.

Y a un mismo tiempo los dos

y el sol me dejan a escuras

en un monte. Ya ¿qué espero?

No fuera andante escudero

a no verme en aventuras

(Calderón, 1691: s.p., vv. 1.051-1.058).

No faltan los habituales recursos para incorporar aquel: el juego de contrarios («parallo» / «andante»), un insinuado contexto metaliterario («aventuras») y la riqueza aliterativa («monte» / «andante»; «oscuras», «espero», «fuera», «escudero», «verme», «aventuras»).

\subsection{FIERAS AFEMINA AMOR}

Otro drama mitológico concebido como fiesta palaciega para su representación en los primeros días de 1670 ofrece en su escena inicial otro caso de «andantes escuderos». La escena, muy espectacular, se construye para «meter» a los espectadores en el espectáculo teatral. En ella sale un león con el que Hércules se va a enfrentar, en recuerdo de uno de sus conocidos doce trabajos. La valentía y arrojo del héroe mitológico se contrasta con el temor y cobardía del criado Licas que se expresa por medio de expresiones interrogativas y exclamativas («¿Quién creerá que es mi miedo / tal al revés de otros que huir no puedo?», [Calderón, 2010: 733, vv. 442-443]; «¡Ay, que le suelta!» [Calderón, 2010: 734 , v. 453]) y de un juego de palabras metaliterario («Luego, ¿desquijarado / hablando hercúleamente, le has dejado?» [Calderón, 1984: 76, vv. 463-464]). Esta comicidad que trae el criado a través de esos recursos es la que prepara la mención de ascendencia cervantina de unos pocos versos después, en boca del mismo personaje. 
Para ejecutar el imperativo de Hércules («Llama, pues ya no hay qué temer, la gente, / que desnudarle de la piel intente / para vestirme de ella, / que es bien, pues que mi estrella / amante me hizo solo de mi fama, / galas usar al gusto de mi dama» [Calderón, 2010: 734, vv. 471-476]), Licas requiere a todos los escuderos que habían huido al aparecer el león (frente a lo que él había hecho, paralizado por el miedo) y con un juego de opuestos que recuerda aquella situación inicial (él se queda parado, los otros salen corriendo) se refiere a ellos:

LiCAS Andantes escuderos,
todo el año pesados y hoy ligeros,
volved y, como si postiza fuera,
destocad al león la cabellera
de testa, y piel. Ya allá lo harán, y en tanto,
para convalecer de aqueste espanto,
¿no será bien, señor, seguir aquella
hermosa tropa bella,
a que nos dé las gracias de haber sido
los dos los que las hemos defendido?
(Calderón, 2010: 734, vv. 477-486).

Todo ello en un contexto, literario y de desarrollo dramático, designado como de «aventuras», de manera que, una vez más, el sintagma se incorpora derivado naturalmente de aquel:

Licas $\quad$ Ya sé que eres
galante cortesano y que es muy justo
alabarte por hombre de buen gusto;
porque ¿quién, empleado en aventuras,
por ver fierezas no dejó hermosuras?

(Calderón, 1984: 78, vv. 512-516).

\section{VOCES DERIVADAS}

Derivada de esta expresión, se hallarán otras voces complementarias, pero que proceden indefectiblemente de aquella; al menos tres: «parante», «viandante» y «muerto andante».

\section{1. «PARANTE»}

Este adjetivo sirve como elemento de contrapunto explícito en una de las maneras en que se incluye el sintagma de ascendencia cervantina; otras veces se hace de manera implícita. Como se indicó más arriba, parece una voz casi exclusiva de 
Calderón que emplea en las comedias ya indicadas, empezando por Basta callar (véase supra). Céfalo y Pocris incorpora la novedad de estar en boca de caballeros, no de criados, aunque el contexto es igualmente cómico y con el complemento de un habitual juego aliterativo sobre las vocales a / e:

$\begin{array}{ll}\text { CÉFAlo } & \begin{array}{l}\text { Dos andantes somos } \\ \text { caballeros de importancia. }\end{array} \\ \text { Rosicler } & \begin{array}{l}\text { Y ya somos dos parantes } \\ \text { a saber lo que nos mandas. }\end{array} \\ \text { Gigante } & \begin{array}{l}\text { Si sois caballeros, ¿cómo } \\ \text { teméis? }\end{array}\end{array}$

(Calderón, 2013: 71, vv. 291-296).

En El escondido y la tapada el juego de contrarios es explícito y, otra vez en boca del gracioso, en una escena que se inicia precisamente con palabras que anticipan la que me ocupa y rodeada de chistes («coche», «ballena», «Juanazos») ${ }^{11}$ :

$\begin{array}{ll}\text { LISARDA } & \text { Para. } \\ \text { BEATRIZ } & \text { ¡Tente, } \\ & \text { borracho! ¿Qué haces? } \\ \text { CÉSAR } & \text { Espera... } \\ \text { MOSQUITO } & \text { Por mi nombre me llamaron. } \\ \text { CÉSAR } & \text {.. que en una zanja de aquéllas } \\ & \text { se ha atascado un coche. } \\ \text { MosQUITO } & \text { Y todo } \\ & \text { sobre el arroyo se vuelca. } \\ \text { CÉSAR } & \text { Mujeres son, fuerza es } \\ & \text { acudir a socorrerlas. } \\ & \text { Vase } \\ \text { MosQUITO } & \begin{array}{l}\text { Dios te haga caballero } \\ \text { parante por su clemencia, } \\ \text { que harto tiempo has sido andante; }\end{array} \\ & \begin{array}{l}\text { ya la encerada ballena, } \\ \text { para escupir sus Juanazos, } \\ \text { por un costado revienta. }\end{array} \\ & \begin{array}{l}\text { Beatricilla es, ¡vive Dios! } \\ \text { la que sacaron primera, } \\ \text { sin duda está aquí su ama }\end{array} \\ & \quad \text { (Calderón, 1989b: 102-104, I, vv. 305-321). }\end{array}$

11 Bien anotados en la edición que utilizo, Calderón (1989b: 192-104). 


\section{2. «VIANDANTE»}

No me cabe duda que esta palabra ha de asimilarse a la expresión objeto de nuestro estudio. Se encontrará en Los tres mayores prodigios (1636), comedia incluida en la Segunda parte (1637). He aquí el texto, que no pasó desapercibido a Santiago Fernández Mosquera (2015: 252-256):

Cantan en el tablado de en medio, y por los otros dos van saliendo en orden las dos compañias, hombre y mujer, cada una en el tablado donde representó, al son de cajas y trompetas.

Músicos

En hora dichosa venga

a estas incultas montañas

el escándalo del tiempo

y el asombro de la fama.

En hora dichosa venga

donde sacrificios haga

de Júpiter en su templo

a la deidad soberana.

JASÓN

Altas cumbres del Oeta...

TEseo

Noble coluna africana...

JASÓN

... que sois descanso del sol,...

TEseo

JASÓN

... que sois de la luna basa,...

TESEO

... decidme si en vuestro centro...

JASÓN

... decid si en vuestras entrañas...

TESEO

... vive el más noble caudillo.

SABAÑóN

... el mejor varón se guarda.

PANTUFLO

Montes de Oeta famosos...

SABAÑóN

Meritísimas montañas...

PANTUFLO

... decid si hay vino en vosotros,

porque yo vengo harto de agua.

Pantuflo $\quad$... decid si para un viandante

habrá en vosotras vianda

y si sufren ancas, que

yo harto estoy de sufrir ancas.

JASÓN Por Hércules os pregunto, moradores desta playa...

Teseo Hércules es el que digo, vecinos destas campañas...

JASÓN $\quad \ldots$ que, aunque vengo en busca suya

sin conseguir la demanda que de él me apartó, porque no ha sido mi dicha tanta, triunfo traigo que rendir a sus generosas plantas $[\ldots]$

(Calderón, 2007: 1.118). 
Entre las intervenciones de los personajes mitológicos se cuelan, como contrapunto burlesco, los graciosos Sabañón y Pantuflo, que se quejan del largo camino recorrido, primero en barco, de ahí el juego entre agua y vino; después a pie (viandante, invocación a las montañas que han de subir para alcanzar el templo de Júpiter), lo que le permite un chiste sobre el hambre que sufren (si habrá vianda), al que se sucede otro en términos similares en el que se unen la referencia al cansancio por el camino recorrido y al hambre insatisfecha en torno a la palabra «ancas». Primero a partir de una frase hecha, aquí utilizada en sentido contrario: si «No sufrir ancas», tal como define el Diccionario de autoridades, 'Metafóricamente se dice cuando una cosa es tan corta que no puede alcanzar más de a lo que está destinada; lo que más regularmente se entiende de las cosas de comer, y en particular de la olla o puchero que uno tiene para su propio sustento y de su familia' (consultado en línea $<$ https://apps2.rae.es/DA.html> [10/06/2021] s.v. «anca»), la expresión del gracioso, expresada sin la negación, se convierte en un deseo o pregunta sobre si las montañas le pueden ofrecer comida en abundancia, ya que vienen molidos y padeciendo de las caderas («ancas»). En definitiva, Calderón ha establecido un juego paralelístico entre dos ideas: cansancio y hambre; la primera expresada a partir de las palabras agua, viandante y ancas; la segunda a partir de las palabras vino, viandas y la expresión hecha «No sufrir ancas» que entrelaza ambas.

\section{3. «MUERTO ANDANTE»}

Se hallará esta expresión en El médico de su honra (¿1629?), incluida en la Segunda parte de comedias (1637):

$\begin{array}{ll}\text { DoÑa MenCía } & \text { Coquín, ¿qué hay, en fin? } \\ \text { Coquín } & \text { Fin al principio en Coquín } \\ & \text { Hay, que esto te estoy contando: } \\ & \text { Mucho el rey me quiere, pero } \\ & \text { Si el rigor pasa adelante, } \\ & \text { Mi amo será muerto andante } \\ & \text { Pues irá con escudero } \\ & \text { (Calderón, 1989a: II, 133, vv. 1.228-1.234). }\end{array}$

En esta ocasión, el sintagma se pone, una vez más, en boca del lacayo, que da principio a su parlamento con un juego de palabras con el final de la intervención previa que sirve de arranque para otro chiste («fin», «principio»), y se refuerza por la rima aguda con el nombre del gracioso. Se sustituye «caballero» por «muerto» (antes se había utilizado el sustantivo «amo» que explicita la relación de servidumbre) manteniendo una similitud fónica con la expresión canónica que se 
complementa con una rima interna («muerto» / «escudero»). Al tiempo, hay una relación directa léxica entre el inicio de la intervención (fin / muerto).

\section{Conclusiones}

Del análisis aquí efectuado pueden extraerse algunas consideraciones sobre la utilización por Calderón de la Barca de la expresión «escudero andante»y derivadas como, por ejemplo, la aparente disminución progresiva del uso de esta expresión: constato cuatro menciones en la década de los años treinta, tres en la década de los años cincuenta y dos en la década de los sesenta. No hay referencia en la cuarta década del siglo XVII. Parece producirse, en efecto, una disminución progresiva, pero tampoco cabe hallar una relación directa entre su utilización y la posible mayor influencia de Cervantes circunscrita, en principio, a unas fechas tempranas de la producción dramática calderoniana. Se trata, cabe plantearlo así, de un recurso que Calderón utiliza con relativa frecuencia a lo largo del tiempo no solo asociado al recuerdo de Cervantes sino por el valor cómico que sabe extraer de él y que quizás se explique por su «especial interés en interactuar con el receptor de su obra en determinada época creativa de su vida, esto es, entre el año 1625 y 1640 aproximadamente» en inteligente propuesta de Vila y Vara (2015: 205).

En relación con el género de las comedias, hay tres casos en las caballerescas, otros tres en las de capa y espada, y dos en las mitológicas, por lo que ha de descartarse que aquel (caballerías en este caso) influya decisivamente en la aparición del sintagma. Por otra parte, «siempre o casi siempre, estas expresiones están en boca del criado y gracioso en consonancia con su función cómica, verdadero personaje marginal en la fábula [...] que encuentra una solidaridad en el espectador» (Hermenegildo, 1995: 231) ${ }^{12}$. Se explica así que, a veces, se incorporen al comienzo de un acto o jornada dentro de un pasaje con abundante contenido cómico para conseguir «meter» al espectador en la comedia que se está representando (Cada uno para sí, El castillo de Lindabridis).

Se emplean al menos en un doble sentido, con frecuencia entrelazado: el que se deriva del concepto literario procedente del Quijote y de los relatos de caballerías aplicado por traslación humorística al escudero; y el que se deriva de su significado literal («andar», «mover», «viajar»), que da lugar a frecuentes —y chistosasquejas de los graciosos por tanto ir y venir siguiendo a sus amos (como aquí, al menos, Basta callar, El escondido y la tapada y Cada uno para si).

12 Arellano, de forma general, sintetizó así el carácter de las referencias concretas de Cervantes en Calderón: «[...] ocurrencias de cariz burlesco, con varios niveles y mecanismos de adaptación (mención general, pie para el ingenio neológico, chiste anacrónico, caracterización de personajes...), y atribuidas en su mayoría a locutores de donaire» (1999: 33). 
Algunas de ellas podrían entenderse como casos de ruptura humorística de la ilusión escénica por reflexión irónica o paródica sobre las propias técnicas del desarrollo dramático, uno de los once medios de comicidad escénica en el teatro de Calderón, con función esencialmente humorística y muy del gusto del público de los corrales de comedias (Arellano, 1986-1999: 308-309).

Para comprender todo el alcance de su incorporación en las comedias se hace imprescindible analizar con detalle el entorno donde aparecen las menciones, incluso la escena o secuencia casi completas, pues se incardinan en un contexto metaliterario a través de un juego de palabras (generalmente por derivación léxica) que le precede y del que son su conclusión o momento culminante. Nunca son traídas de manera extemporánea como algo ajeno, sino entrelazadas hábilmente con lo acontecido antes, tanto desde el punto de vista formal como también de contenido y desarrollo de la acción. De ahí el uso constante de juegos aliterativos, de palabras, de contrarios, estructuras repetitivas, refranes y políptotos, lo que da cabida a que la incorporación del sintagma se conciba en forma de oposición explícita («andante» / «parante») o implícita («andante» / «lacayo de cura viejo»).

Todo esto permite, desde otra perspectiva, incorporar el estudio que hoy ofrezco al fértil campo de la reescritura de nuestros clásicos y, de manera más acotada, a la auto-rescritura de Calderón quien, en efecto, con Vitse, es «[...] por antonomasia el dramaturgo áureo de la reescritura» (1998: 6). El uso y alcance, a través del tiempo, del sintagma «escudero andante», sus variaciones y expresiones complementarias («parante», «viandante», «muerto andante») han de entenderse como muestras de la técnica de «repetición-variación» (Vega GarcíaLuengos, 2013: 139), del «aprovechamiento de una escena o pasaje textual en diferentes piezas teatrales» (Ruano de la Haza, 1998: 35-36), de la utilización, en fin, de material anterior que «abarca cualquier cosa, desde el vocabulario a la fraseología, las bromas, las situaciones y argumentos enteros» (Cruickshank, 2011: 204-205). Un Calderón, en fin, que se usaba mucho a sí mismo, que trasvasa a la comedia una expresión procedente de la prosa de ficción de aquel tiempo $\mathrm{y}$, una vez constatadas sus posibilidades, la reutiliza con profusión sin límites cronológicos, genéricos o de otro tipo; un hallazgo feliz que, comprobada su eficacia cómica, reiterará con frecuencia ${ }^{13}$. En definitiva, acaba importando menos la dependencia cervantina cuanto la eficacia de un mecanismo de reescritura que Calderón maneja con habilidad y soltura.

13 Véase, complementariamente, Granja (2000) y Fernández Mosquera (2015: 81-104). 
BIBLIOGRAFÍA

Abrams, Fred (1966). «Imaginería y aspectos temáticos del Quijote en El alcalde de Zalamea». Duquesne Hispanic Review, 5, pp. 27-34.

Arellano, Ignacio (1986-1999). «La comicidad escénica en Calderón». En Convención y recepción. Estudios sobre el teatro del Siglo de Oro. Madrid: Gredos, pp. 264-316.

Arellano, Ignacio (1999). «Cervantes en Calderón». Anales Cervantinos, 35, pp. 9-35.

Calderón de la Barca, Pedro (1691). Novena parte de comedias Novena parte de Comedias de don Pedro Calderón de la Barca. Madrid: Francisco Sanz $<$ http://www.cervantesvirtual.com/obra/el-castillo-de-lindabridis/> [Consulta: $10 / 06 / 2021]$.

Calderón de la Barca, Pedro (1982). Cada uno para sí. José María Ruano de la Haza (ed.). Kassel: Edition Reichenberger.

Calderón de la Barca, Pedro (1984). Fieras afemina amor. Edward M. Wilson (ed.). Kassel: Edititon Reichenberger.

Calderón de la Barca, Pedro (1989a). El médico de su honra. D. W. Cruickshank (ed.). Madrid: Castalia.

Calderón de la Barca, Pedro (1989b). El escondido y la tapada. Maravillas Larrañaga Donézar (ed.). Barcelona: Promociones y Publicaciones Universitarias.

Calderón de la Barca, Pedro (1989c). La fiera, el rayo y la piedra. Aurora Egido (ed.). Madrid: Cátedra.

Calderón de la Barca, Pedro (2000). Basta callar. Margaret Rich Greer (ed.). Ottawa: Devehouse Editions.

Calderón de la Barca, Pedro (2006). Peor está que estaba. Primera parte de comedias. Madrid: Biblioteca Castro / Fundación José Antonio de Castro, pp. 860-951.

Calderón de la Barca, Pedro (2007). Segunda parte de comedias. Santiago Fernández Mosquera (ed.). Madrid: Fundación José Antonio Castro / Biblioteca Castro.

Calderón de la Barca, Pedro (2010). Sexta parte de comedias. José María Viña Liste (ed.). Madrid: Fundación José Antonio Castro / Biblioteca Castro.

Calderón de la Barca, Pedro (2013). Céfalo y Pocris. Enrica Cancelliere e Ignacio Arellano (eds.). New York: Instituto de Estudios Auriseculares.

Calderón de la Barca, Pedro (2016). El alcalde de Zalamea. José Montero Reguera (ed.). Madrid: Castalia.

Calderón de la Barca, Pedro (2017). Amor, honor y poder. Zaida Vila Carneiro (ed.). Madrid / Frankfurt am Main: Iberomericana / Vervuert.

Canavaggio, Jean (1988). «En torno al Dragoncillo». En Alberto Navarro (ed.), «Nuevo examen de una reescritura». Estudios sobre Calderón. Salamanca: Universidad de Salamanca, pp. 9-16.

Cervantes, Miguel de (2015). Don Quijote de la Mancha. Francisco Rico (ed.). Madrid: Real Academia Española.

Close, Anthony (2011). «Novela y comedia de Cervantes a Calderón: el caso de La dama duende». En Aurora Egido (ed.), Lecciones calderonianas. Zaragoza: Ibercaja, pp. 33-52.

Cruickshank, Don W. (2011). Calderón de la Barca. Madrid: Gredos. 
Díez Borque, José María (2000). «Calderón de la Barca y la novela de caballerías (breve nota)». Bulletin of Hispanic Studies, 77: 1, pp. 255-264.

Escalonilla López, Rosa Ana (2002). «El paradigma de la caricatura quijotescocervantina en el teatro de Calderón». EPOS, 18, pp. 145-61.

Fernández de Avellaneda, Alonso (2014). Segundo tomo del ingenioso hidalgo don Quijote de la Mancha. Luis Gómez Canseco (ed.). Madrid: Real Academia Española.

Fernández Mosquera, Santiago (2015). Calderón, texto, reescritura, significado y representación. Madrid / Frankfurt am Main: Iberoamericana / Vervuert / Universidad de Navarra.

Granja, Agustín de la (2000). «Este paso ya está hecho: Calderón contra los mosqueteros». Estudios sobre Calderón. Madrid: Ediciones Istmo, t. 1, pp. 160-190.

Hermenegildo, Alfredo (1995). Juegos dramáticos de la locura festiva: pastores, simples, bobos y graciosos del teatro clásico español. Palma de Mallorca: José J. de Olañeta.

Iglesias Feijoo, Luis (2006). «Introducción». Pedro Calderón de la Barca, Primera parte de comedias. Madrid: Biblioteca Castro / Fundación José Antonio de Castro, pp. IX-LVII.

Iglesias Feijoo, Luis (2004). «Calderón, ayer y hoy. Sobre el origen romántico de la visión actual de Calderón». En José María Díez Borque y José Alcalá-Zamora (coords.), Proyección y significados del teatro clásico español. Homenaje a Alfredo Hermenegildo y Francisco Ruiz Ramón. Madrid: Sociedad Estatal para la Acción Cultural Exterior, pp. 139-159.

Iglesias Feijoo, Luis (2016 [2002]). «Calderón y el humor». El viaje entretenido. Estudios de literatura española compilados en homenaje a su autor. Santiago de Compostela: Universidade de Santiago de Compostela, pp. 329-348.

LeiJA, Ana Lorena (2009). «La guerra civil y el torneo a muerte en El castillo de Lindabridis de Calderón de la Barca: adaptación y realización escénica». Anuario Calderoniano, 2, pp. 219-230.

Londero, Renata (1998). «La puente de Mantible de Calderón y la Historia del Emperador Carlo Magno: comedia caballeresca y libros de caballerías». En María Cruz García de Enterría y Alicia Cordón Mesa (eds.), Siglo de Oro. Actas del IV Congreso internacional de Asociación Internacional del Siglo de Oro. Alcalá de Henares: Universidad de Alcalá, t. 2, pp. 899-908.

Madroñal Durán, Abraham (2005). «Entre Sancho Zancas y Juan Rana». En Luciano García Lorenzo (ed.), La construcción de un personaje: el gracioso. Madrid: Editorial Fundamentos, pp. 141-165.

Madroñal Durán, Abraham (2012). Seis estudios en busca de un actor. Juan Rana y el entremés del siglo XVII. Madrid: Ediciones Clásicas.

Meregalli, Franco (1995). «Cervantes en Calderón». En Antonella Cancellier, Donatella Pini Moro y Carlos Romero (eds.), Atti delle Giornate Cervantine. Padua: Unipress, pp. 127-135.

Montero Reguera, José (1997). El Quijote y la crítica contemporánea. Alcalá de Henares: Centro de Estudios Cervantinos. 
Montero Reguera, José (2005a). El Quijote durante cuatro siglos: lecturas y lectores. Valladolid: Universidad de Valladolid.

Montero Reguera, José (2005b). «Una cala en la prosa eufónica del Quijote: los epígrafes de la primera parte». En Augustin Redondo (dir.), Releyendo el Quijote, cuatrocientos años después. Alcalá de Henares: Centro de Estudios Cervantinos / Presses Sorbonne Nouvelle, pp. 13-23.

Montero Reguera, José (2011). Cervantismos de ayer y de hoy: capitulos de historia cultural hispánica. Alicante: Universidad de Alicante.

Regalado, Antonio (1999). «Cervantes y Calderón: el gran teatro del mundo». Anales Cervantinos, 35, pp. 407-417.

Rico, Francisco (1990). Texto y contextos. Estudios sobre la poesía española del siglo XV. Barcelona: Crítica.

Rodríguez Gallego, Fernando y Adrián J. SÁez (eds.) (2016). Pedro Calderón de la Barca, La puente de Mantible. Madrid / Frankfurt am Main: Iberoamericana / Vervuert.

Ruano de la Haza, José María (1998). «Las dos versiones de El mayor monstruo del mundo, de Calderón». Criticón, 72, pp. 35-47.

SÁEz, Adrián J. (2013). «Reescritura e intertextualidad en Calderón: No hay cosa como callar». Criticón, 117, pp. 159-176.

SÁnchEZ, Alberto (1957). «Reminiscencias cervantinas en el teatro de Calderón». Anales Cervantinos, 6, pp. 262-270.

SuÁrez Miramón, Ana (1999). «Cervantes en los autos sacramentales de Calderón». Anales Cervantinos, 35, pp. 511-537.

Torres, José Carlos de (1998a). «"Enquijotóse mi amo” o el tema del caballero idealista en las comedias de Calderón». En Antonio Bernat Vistarini (ed.), Actas del Tercer Congreso Internacional de la Asociación de Cervantistas (III-CINDAC). Mallorca: Universidad de las Islas Baleares, pp. 619-629.

Torres, José Carlos de (1998b). «Adiciones al tema de las citas cervantinas en Calderón: las cita sobre Lope de Vega». Anales Cervantinos, 35, pp. 571-584.

Torres, Victoria B. (ed.) (1987). Pedro Calderón de la Barca, El castillo de Lindabridis. Pamplona: EUNSA.

Valbuena Briones, Ángel (1965). Perspectiva crítica de los dramas de Calderón. Madrid: Rialp.

Valbuena Briones, Ángel (1977). Calderón y la comedia nueva. Madrid: Espasa-Calpe.

Vega García-Luengos, Germán (2013). «El Calderón que olvidó o repudió Calderón». En Alain Bègue y Emma Herrán Alonso (dirs.), Pictavia aurea. Actas del IX Congreso de la Asociación Internacional «Siglo de Oro» (Poitiers, 11-15 de julio de 2011). Toulouse: Presses Universitaires du Mirail, pp. 111-142.

VILA CARNEIRO, Zaida y Alicia VARA LóPEZ (2015). «Aproximación a las referencias metateatrales en los finales de las comedias calderonianas». Anuario Calderoniano, 8, pp. 195-208.

Vitse, Marc (1984). «Reseña a Pedro Calderón de la Barca. Cada uno para sí. A critical edition, with introduction, including a study of the transmission of the text, and notes, by José María Ruano de la Haza. Kassel: Edition Reichenberger, 1982». Criticón, 27, pp. 109-128. 
Vitse, Marc (1998). «Presentación». Criticón, 72, pp. 5-10.

WiLson, Edward M. (1982). «Calderón y Cervantes». En Hans Flasche y Robert D. F. Pring-Mill (eds.), Hacia Calderón. Quinto Coloquio Anglogermano Oxford 1978. Wiesbaden: Franz Steiner Verlag, pp. 9-19.

Recibido: 19/01/2021

Aceptado: 11/02/2021 


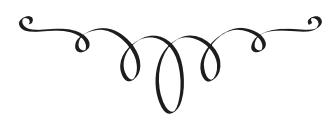

\section{La Andante escudería de don Pedro Calderón de la Barca}

RESUMEN: Se estudia aquí un detalle mínimo, una expresión y algunos de sus derivados que ofrecen un aspecto más del intenso eco que Cervantes, sobre todo el Quijote, tiene en el teatro de Calderón; refuerza, por una parte, la idea comúnmente asentada del modo con el que se recibió el libro del alcalaíno: para hacer reír, con sentido cómico. De otra parte ofrece un pequeño corpus de cómo Calderón encuentra en la literatura cervantina elementos diversos que contribuyen a enriquecer la parte cómica de sus comedias, a potenciarla, en todo caso. En otras palabras: lo que Calderón usa en su teatro procedente de Cervantes va generalmente unido a lo cómico.

Palabras clave: Cervantes, Calderón, Don Quijote de la Mancha, recepción, léxico.

The «SQuire-errantry» of Pedro Calderón de la Barca

ABSTRACT: A minimal detail, an expression and some of its derivatives are studied in this paper that offers one more aspect of the intense echo that Cervantes, especially Don Quixote, has in the theater of Calderón; on the one hand, it reinforces the common idea established in the way in which the book was received: to make people laugh, with a comic sense. On the other hand, it offers a small corpus of how Calderón finds in cervantine literature diverse elements that contribute to enrich the comic part of his comedies; to enhance it, in any case. In other words, what Calderón uses in his theater from Cervantes is generally linked to the comic.

Keywords: Cervantes, Calderón, Don Quijote de la Mancha, reception, lexicon. 